\title{
A Study on Teacher Feedback on EFL Writing of Non- English Majors
}

\author{
Miao Wang \\ Nan Yang Institute of Technology, Nanyang 473000, China \\ wmaugust1982@163.com
}

Keywords: teacher feedback, English writing, Non-English majors.

\begin{abstract}
English writing, an important means of communication and a significant skill, must be grasped by the English learners. In China, writing has always been the weakest link in the English teaching. Given this, the paper designs empirical study to probe the effects of four kinds of teacher feedbacks (form feedback, content feedback, form combined content feedback and no feedback) on the Chinese EFL learner' English writing. Qualitative and quantitative measures are employed. The instruments are pre-test, post-test, experimental student's questionnaire along with the interview. According to the quantitative and qualitative results, the author finds that most students want to receive feedback from teachers. The favorite teacher feedback is the form combined content feedback. Students with the higher-level incline to pick content feedback, while students with the relative lower level tend to choose form feedback. Content feedback has positive impacts on the content scores, meanwhile, the form feedback made significant improvement on the formal accuracy.
\end{abstract}

\section{Introduction}

There is no denying that teacher feedback is predominant link in college English writing with the direction of the process approach. At any stage of writing, the feedback from teacher will affect your writing, for example the teacher will read your draft and correct and proofread your product.

Moreover, the teacher responses are important input for you to receive information from your reader especially for non-English majors. But, in EFL-context in reality, about the teacher feedback, there exist gap between students and teacher. Some students show no concern about nothing but the scores, while others are blind to the correction of teacher. So, it is high time for us know what kind of feedback are in need of in the students' eyes (form feedback or content feedback) and prove the effects of teacher feedback by the experiment. However, in China, few studies are carried out about the students' perceptions towards the teacher feedback, from this point, the research based on Nanyang Institute of Technology, is unique and meaningful. Undoubtedly speaking, this thesis's results definitely will make great contribution to the author's college in non-majors' English writing and accelerate the English acquisition and propose some constructive advice to EFL writing for non-English majors in China based on the findings of the study. The present study attempts to achieve a relatively reliable result based on the findings above. The significance of the present study lies in the investigation of the EFL learners' writing rather than ESL learners' writing, which makes it different from almost all the previous international researches made so far. The reason is that the language learning environment for EFL students is quite different from that for ESL students, thus to certain extent leading to different findings.

\section{Subjects}

The subjects of the experiment were 44 full-time juniors choosing from two parallel classes of 12 boys and 32 girls majoring bromatology in Grade 2009 from Nan Yang Institute of Technology, in Henan province. These students were selected because they have the same teacher and the same 
class time also, moreover, CET-4 scores and final examinations scores (according to their writing scores in the latest CET-4 and the final tests of last semester) were closer at low intermediate level. Ranging from 19 to 21 in terms of age, subjects have been learning English for 8 years.

\section{Research Questions and Methodology}

Three questions involved in this experiment are as follows:

(1) Can different types of teacher written feedback make significant changes in quality of students' argument writing?

(2) What are the impacts of four kinds of teacher feedback on formal accuracy and content quality of students' writings?

(3) What are students' perceptions, attitudes, and expectations from the different types of teacher feedback based on Nan yang Institute of Technology?

Based on the theory of Process Writing theory and Output Hypothesis, the researcher makes an empirical study on college English writing aiming at finding the effects of different teacher treatments on non-English majors' English writing ability. And the research methods employed are as follows:

\subsection{Test}

Two tests, namely the pre-test and the post-test, serve to work out whether the experimental class and the control class are of the same level in terms of English wring and whether learners' English wring competence will be improved after about 16-week experiment.

\subsection{Questionnaire and the Interview}

As the qualitative research methods, the questionnaire aiming to obtain a general idea of students' opinions and inclinations towards the different teacher feedbacks is distributed to only the experimental class and the interview is employed to retest the effects of teacher feedback and elicit some suggestions to teacher feedback.

\section{Research Design}

The 44 students were randomly divided into three experimental groups and one control group. The four groups respectively received different kinds of teacher treatments on their compositions. Group one received form feedback, group two received content feedback, group three received both the form feedback and content feedback, and group four received no feedback as a control group. Participants were in the sixth-semester of an academic year 2011-2012 when the experiment begun, besides, the class was taught by the author and the subjects met twice a week nearly for two hours in the integrated English class and approximately for two hours in autonomic learning class and each period lasted one hour. According to the textbook, (New College English Integrated Course 3 Student's Book) there were altogether 8 units and each unit included two texts, which should be finished in 16 weeks. What's more, there was no exclusively English writing class in the Nan Yang Institute of Technology. Therefore, so the author of the thesis made use of the two periods of class for autonomic learning on Thursday night to train writing skills. That is to say, at least 100minutes were spent each week on the teaching of English writing based on the process-oriented theory. In the first 50 minutes, the teacher systematically gave a series of writing skills, by the sequence of diction, sentences, paragraphs up to the whole composition, the criteria of good writing, including outline, argumentation, topic sentences transition, cohesion, supporting an argument, and unity, in English as well as the writing titles. In the rest of 50minutes, the subjects were asked to finish their own writing by themselves and hand in their products. The teaching methodology involved teacher instruction for about $50 \%$ of the time and students practicing writing for the rest, which provided an ideal setting for the implementation of the experiment.

In the experiment, there were three experimental groups and a control groups. 
Table1 treatments of different groups

\begin{tabular}{c|c}
\hline Group & treatment \\
\hline G1 & direct feedback \\
\hline G2 & content feedback on content, idea, structure \\
\hline G3 & form combined content feedback \\
\hline G4 & no feedback \\
\hline
\end{tabular}

\subsection{Tests}

Before the adoption of different teacher feedbacks, the author designed the writing task to test the subjects in order to ensure the consistency of the English proficiency and writing level. The author requested the students to write a composition entitled "Students' Pursuit for Famous Brands" at least 130 words and invited her director of the English department, as a rater, to supervise the students to finish on their own rather than the author did not grade the papers, another rater, an experienced teacher aged 40 from Nanyang Normal University, rated the compositions. The full score of the writing was 15 points.

In the fifteenth week, the author asked the participants to accomplish the post-test writing task no less than 130 words. The title of writing is "Should Cars be Allowed into College Campus"? and the full score of the writing was 15 points. The post-test was to examine the effects of different treatments on the subsequent writing and to decide whether the three were significantly differences among the four groups. The supervisor and the rater of the post-test were the same persons with the pre-test.

\subsection{Questionnaire}

The author had carefully studied the questionnaire of the Ferris (1995), Lee (2004) and Wang (2007) about the teacher feedback, according to the research content of the present study, the student questionnaire was somewhat modified in this study by the researcher. The questionnaire was conducted by the experiments participants after the completion of the seventh composition task. The purpose was to figure out students' inclination to like which types of teacher feedback, meanwhile, the result can act as a guideline for L2 writing teachers to organize their subsequent teaching.

All the close-ended questions in the questionnaire with were devised in Chinese for the convenience of student understanding and were filled out by the experimental students within 10minutes. The questionnaire was made up of 13 items. It consisted of four parts. Part one was about the basic information of the participants, such as gender self-ratings as English learners, the score of his or her latest CET4, as well as the score of writing part. The second part investigated their overall attitudes towards English writing. The third part elicited students' perceptions and attitudes towards the different kinds of feedback in terms of form and content and self-evaluation of their English level. The fourth part studied students' expectations and preferences from teachers, etc.

\subsection{Interview}

In the sixteenth week, the author at random picked out six students belonging to three different levels(two are at relative high level, two are at intermediate level, two are at low level)from the three experimental groups and carried out a semi-structured interview to figure out their reactions to teacher feedback when revising the composition, to re-test the students' attitudes and preferences towards teacher feedback, to explore the students further suggestions about teacher feedback. In the light of the opinions of interviewees, the time period was basically controlled within 20minutes.

\section{Conclusion}

We can achieve some major findings in the process of probing the three questions according to the above quantitative and qualitative analysis. 
First, students look forward to receiving teacher feedback in hopes of acquiring improvement on their writing. As to different kinds of teacher feedback, the most welcomed by the students is the form combined the content feedback. The favorite form-focused feedback and the content-focused feedback respectively direct feedback and the marginal plus end comment type of content-focused feedback.

Second, different students have diversified demands towards teacher feedback according to their English writing level. The students with somewhat higher English level incline to pay more attention to the content and structure of their writings and thus opt for the type of feedback that includes content-focused feedback; while those with relatively poor language ability prefer the form-focused feedback.

Third, though being questioned by many scholars, form-focused feedback is effective in improving student writing's formal accuracy. In the present study, the form feedback-providing has proved to be effective due to the students' excessive attention to the grammatical problem, universally speaking, in the English class in China, most of the EFL students hope the teacher to teacher more grammar knowledge rather learning skills.

Lastly, all the three treatments have made the students to gain the improvements on the means of the content and form. The form \& content combined feedback turn to be the most effective type, the G3 receiving this type of feedback has obtained the most significant changes on both form and content quality.

\section{References}

[1] Ash well, T. Patterns of Teacher Response to Student Writing in a Multiple-Draft Composition Classroom: Is Content Feedback Followed by Form Feedback the Best Method? [J]. Second Language Writing, 2000(9): 227-257.

[2] Chandler, J. The Efficacy of Various Kinds of Error Feedback for Improvement in the Accuracy and fluency of L2 Student Writing [J]. Second Language Writing, 2003. (3), 267-296.

[3] Hyland, F. Focus on form: Student Engagement with Teacher Feedback [J]. System, 2003, (31/2): 217-230.

[4] William, J. Undergraduate Second Language Writers in the Writing Center [J]. Journal of Basic Writing, 2002(21/2): 73-91.

[5] Lewis, M. Giving Feedback in Language Classes [M]. Beijing: People’s Education Press, 2007. 